\title{
REVISITANDO A TEORIA DA SEPARAÇÃO ENTRE OS PODERES ${ }^{1}$
}

\author{
Eduardo K. M. Carrion²
}

Prezado Dr. Luiz Fernando Calil constituir-se em efetiva república, no de Freitas, que preside a mesa; prezada significado de prevalência, na ordem Dra. Fabiana Azevedo da Cunha Barth, política, do interesse público sobre Presidente da APERGS, entidade o interesse privado e, respeitando a promotora, através da ESAPERGS, etimologia da expressão, no sentido deste importante evento; estimado de ideia de coisa pública ou de coisa colega e amigo Dr. Clèmerson Merlin comum; enfim, a perspectiva do bem Clève; prezado Dr. Luis Roberto comum, nem que seja como sonho Barroso, homenageado do evento. acalentado.

Senhoras e Senhores.

Professor Clèmerson, professor

Em tempos de descaso com a coisa Barroso, nossos convidados: constitui pública, seria pertinente relembrar a lição sempre atual de Rui Barbosa, no início do século passado, de que o Brasil tem se caracterizado antes por ser uma reprivada do que por de fora, com a audição do hino rio-

1 Intervenção ocorrida em 17.09.2009 por ocasião do III Congresso Internacional Revisitando o Direito Público, Painel: Interfaces entre Poder Executivo e Poder Legislativo, realizado na Faculdade de Direito da UFRGS, promoção da Associação dos Procuradores do Estado do RS (ESAPERGS) e Procuradoria-Geral do Estado do RS (PGE-RS). Texto revisado. Manteve-se, entretanto, a forma coloquial da exposição.

2 Professor Titular de Direito Constitucional e ex-Diretor da Faculdade de Direito da UFRGS. 
grandense-do-sul. Hino de marca, de diapasão militar, como costumam ser muitas vezes os hinos. Daí, talvez, o exagero de algumas palavras. No nosso caso, "sirvam nossas façanhas de modelo a toda a terra". Pois bem, nessa semana mesmo, fomos privilegiados por ouvir nas rádios locais a reprodução de gravações autorizadas pela justiça que, segundo o Ministério Público Federal, diriam respeito a tratativas de corrupção de políticos estaduais, em que tínhamos como fundo musical o hino riograndense-do-sul: "Sirvam nossas façanhas de modelo a toda terra”. A ser assim, pobre humanidade... A ser assim, parece que estaremos a negar, aqui no Rio Grande do Sul, nossas tradições castilhistas (Júlio Prates de Castilhos, 1860-1903, Presidente do Estado em 1891, cuja trajetória e ideário marcou decisivamente a política gaúcha desde então, sobretudo durante a $1^{\mathrm{a}}$ República) e republicanas. Por tudo isso, muito me honraria que a apresentação de meu currículo se limitasse a uma única expressão: "Republicano”.

Aproveito essas observações para relembrar algumas palavras do Ministro Rubens Ricúpero em artigo na Folha de São Paulo deste último domingo (13.09.2009), pertinentes para o tema desta manhã: “A corrupção passou a ser condição da governabilidade. É essa a justificativa de dirigentes de partidos do governo para sua cumplicidade no enterro dos escândalos parlamentares. A diferença com o regime militar é uma só: substituíram-se a violência e a tortura pela corrupção como suposta condição para ter segurança e governar. Corrupção e violência, ensinava o filósofo Norberto Bobbio, são os dois tipos de câncer que destroem a democracia. No regime militar, sacrificou-se a democracia em nome da segurança, elemento da governabilidade. Hoje a situação mudou e se usa o mesmo pretexto para fazer engolir o conluio ou a indulgência com a corrupção". E conclui o Ministro: "Não sendo apanágio apenas de um governo, o vício se agrava ano a ano. Nem a seriedade dos últimos escândalos, que comprometem instituições inteiras, conseguiu alterar a complacência dos governos, que pode não ser eterna, mas tem se revelado infinita enquanto dura”.

Bem, o que observamos é que, por mais que a Constituição, e isso o fez a Constituição de 1988, arme o Poder Legislativo com mecanismos de fiscalização e de controle do Poder Executivo - poderíamos até dizer que, por vezes, a Constituição de 1988 ensaia mesmo um cogoverno entre Executivo e Legislativo -, por mais que ela apresente perspectivas inovadoras, as práticas institucionais, o costume constitucional reiteram em certo sentido a experiência de 
um presidencialismo imperial, o que remete às nossas raízes históricas. Tinha assim razão Raimundo Faoro quando tentava compreender o país dos anos 50, remontando a história portuguesa do final do século XIV.

A revolução de 1383 em Portugal explica o fortalecimento do absolutismo, do estado absolutista na península ibérica, e o nosso estado colonial sendo em grande parte uma continuidade com relação a essa experiência ibérica, o que repercute na experiência republicana, construindo praticamente um presidencialismo imperial.

A ideia de separação de funções e de poderes estatais remonta à antiguidade clássica, mas um dos seus grandes sistematizadores foi sem dúvida Montesquieu em Do Espírito das Leis, de 1748. Entretanto, o que na realidade encontramos em Montesquieu não constitui propriamente uma teoria da separação dos poderes, mas antes uma doutrina da colaboração entre os poderes, tal como destacado no trabalho clássico de Charles Eisenmann L' 'Esprit des Lois' et la séparation des pouvoirs de 1933, argumentação essa retomada num segundo texto $L a$ pensée constitutionnelle de Montesquieu de 1952, ambos marco de interpretação da obra de Montesquieu. Reflexão essa, aliás, também retomada pelo filósofo Louis Althusser no ensaio Montesquieu. La politique et l'histoire de 1959.
Destaco do texto de 1933 de Charles Eisenmann algumas poucas passagens: “Assim o regime constitucional descrito no Do Espírito das Leis não é um regime da separação das autoridades estatais”; mais adiante: “Assim, a ideia de separar as autoridades estatais está completamente ausente de Do Espírito das Leis: ela não se encontra aí nem apresentada, nem formulada”.

Nem apresentada, nem formulada. Concluindo, a última frase destacada do importante texto: "Devemos, pois, renunciar, se temos a preocupação de uma terminologia exata, a designar o sistema de Montesquieu pelo nome de sistema da separação dos poderes”.

Efetivamente, basta lermos o Capítulo VI - Da Constituição da Inglaterra do Livro Décimo Primeiro de Do Espírito das Leis para nos certificarmos de que se trata na realidade de uma doutrina da colaboração entre os poderes e não de uma teoria da separação dos poderes.

O dogma ou a teoria da separação dos poderes foi em grande parte uma construção do direito público revolucionário. Tornava-seimportante, num contexto de parlamentarismo dualista, afirmar a independência e a soberania do Poder Legislativo.

A Constituição francesa de 1791, por exemplo, chegou ao detalhe, ao requinte de, na eventualidade de um parlamentar assumir um cargo no Executivo, perder automaticamente o 
mandato, o que, aliás, poderia ser uma boa alternativa para os dias de hoje no Brasil. Para exatamente afastar qualquer tentativa de cooptação do Legislativo por parte do Executivo. Para finalmente evitar relações espúrias entre Legislativo e Executivo, tal como estamos acostumados no Brasil nos três planos do estado federal: União Federal, Estados Membros e Municípios.

$\mathrm{O}$ que encontramos efetivamente na realidade institucional e política da democracia moderna é um sistema de colaboração entre os poderes, de exercício de múltiplas funções, legislativas, político-administrativas e mesmo jurisdicionais por parte dos distintos poderes. Muitas vezes, como recurso didático, recorremos à tentação, à facilidade de distinguir para os alunos o exercício das denominadas funções típicas e atípicas de cada um dos poderes, o que, na realidade, revela-se completamente falso. Como posso afirmar, que funções políticoadministrativas, funções materiais exercidas pelo Congresso Nacional e suas duas Casas, tal como se expressam nos artigos 49, 51 e 52 da Constituição, funções essas em grande parte de controle e de fiscalização da ação e das políticas do Executivo, por exemplo, de aprovação da lei orçamentária anual e de seu acompanhamento, sejam funções atípicas, sugerindo a ideia de atividade acessória ou secundária. As denominadas funções atípicas exercidas por cada um dos poderes constituem funções essenciais, exatamente porque o ponto de referência não é uma teoria da separação dos poderes, mas sim uma doutrina da colaboração entre poderes. Isso tudo está claramente presente na obra de Montesquieu.

Nossa constituição avançou significativamente nesse sentido e nessa compreensão. Um dispositivo que merece ser ressaltado hoje na Constituição de 1988 diz respeito à possibilidade de o Congresso Nacional, através de decreto legislativo, "sustar os atos normativos do Poder Executivo que exorbitem do poder regulamentar ou dos limites delegação legislativa” (Artigo 49, V). Procedimento de controle de constitucionalidade por órgão político, no caso o Legislativo (Congresso Nacional), e repressivo. Na realidade, tratou-se de retomada de instituto análogo já criado pela Constituição de 1934 (“Artigo 91. Compete ao Senado Federal: ... II, examinar, em confronto com as respectivas leis, os regulamentos expedidos pelo Poder Executivo, e suspender a execução dos dispositivos ilegais”), instituto não reproduzido pelas Constituições posteriores, razão de se poder falar em criação ou, pelo menos, em recriação do instituto. Entretanto, no contexto da Constituição de 1934, tratava-se de mecanismo de controle de legalidade, no contexto da Constituição de 1988, 
trata-se, ao contrário, de mecanismo de controle de constitucionalidade. Além disso, enquanto que, sob a égide da Constituição de 1988, diz respeito tanto a regulamentos do Executivo como a leis delegadas, sob a égide da Constituição de 1934 dizia respeito apenas a regulamentos do Executivo, mesmo porque a lei delegada, assim como a lei complementar só vieram a ser criadas pela $E C n^{\circ}$ 4, de 02.09.1961.

A Constituição de 1934 já introduzira mecanismos ou corretivos parlamentaristas no contexto de um sistema presidencial de governo, ou seja, o reforço das funções de controle e de fiscalização da ação e das políticas do Executivo. A Constituição de 1988 torna-se generosa a esse propósito, pois essa última instrumentalizou, armou o Congresso Nacional e suas duas Casas com inúmeros procedimentos para melhor responsabilizar o Poder Executivo, de tal forma que as decisões administrativas não se tornassem sempre decisões solitárias do Presidente da República.

A par disso, criaram-se igualmente mecanismos de participação social, a criação de inúmeros conselhos sociais de forma a responsabilizar permanente, cotidianamente a administração pública nas mais diversas esferas.

Constatados os limites, no contexto de uma sociedade complexa como a contemporânea, dos procedimentos da democracia meramente representa- tiva - alguns referem-se mesmo a uma crise de representação das democracias -, foram criados novos mecanismos e organismos de forma a assegurar uma melhor mediação entre o Estado e a Sociedade Civil e na perspectiva de uma democracia participativa têm sido propostos. Entre eles, exatamente os denominados conselhos sociais ou ainda conselhos populares ou, mais precisamente, conselhos com participação da comunidade, as autoridades administrativas independentes da linguagem jurídica, categoria nova em que pese se referir muitas vezes a experiências mais antigas, cujo objetivo seria o de procurar favorecer um maior controle social da administração pública.

São geralmente instituídos em áreas sensíveis da atividade social, das liberdades públicas e dos direitos sociais à política de desenvolvimento, com o intuito de evitar a tutela direta ou demasiada do poder público. Limite à ação dos governantes, através de uma maior participação social, ensejam tanto a superação da oposição público x privado, como a despartidarização relativa das funções estatais. Abrandam assim o monolitismo tradicional da administração pública no sentido de um modelo pluralista ou policêntrico de Estado em contraponto ao modelo unitário anterior. Organismos esses que se diferenciam dos simples conselhos consultivos, possuindo um verdadeiro poder de decisão. 
Trata-se de um efetivo direito de participação de certas entidades na definição de políticas públicas. Direito esse que se radica nas ideias de democratização do Estado e de aprofundamento da democracia participativa. Através desse direito de participação, ele mesmo direito fundamental, asseguram-se melhor os direitos fundamentais constitucionalmente prescritos. Como assinala com precisão Canotilho, sem o direito de participação de certas entidades na definição de políticas públicas "os cidadãos permanecem afastados das organizações e dos processos de decisão, dos quais depende afinal a realização dos seus direitos. ... Quer dizer: certos direitos adquiriam maior consistência se os próprios cidadãos participassem nas estruturas de decisão (CANOTILHO, J. J. Gomes. Direito Constitucional. 5.ed. Coimbra: Almedina1991, p. 558)”. Diz respeito à dimensão processual participativa (aquilo que Häberle, citado por Canotilho, designou como status activus processualis) dos direitos fundamentais, dimensão essa profundamente renovadora das concepções dos direitos fundamentais.

Conspiram, entretanto e em grande parte, com relação ao desiderato constitucional, as práticas institucionais, reiterando a histórica experiência de um presidencialismo imperial, o que remete a uma discussão, no plano da teoria constitucional, referente às chamadas modificações não formais das constituições ou modificações informais das constituições ou, ainda, segundo alguns outros, mutações constitucionais, uma expressão que não me parece ser a mais adequada para expressar a generalidade do fenômeno, já que nem todas as modificações não formais das constituições caracterizam-se como inconstitucionais. Ao importar uma expressão de uma área do conhecimento para outra, muitas vezes carregamos certos atributos que eram próprios de um contexto científico determinado para outro quadro científico distinto. A mutação na ciência biológica, na genética significa uma ruptura na transmissão do código genético, distinta da replicação, sugerindo a ideia de irregularidade. Porém, nem todas as denominadas mutações constitucionais são inconstitucionais; algumas são perfeitamente constitucionais, haja vista a jurisprudência dos Tribunais Constitucionais contemporâneos, em grande parte avançando com relação a uma interpretação estritamente silogística ou literal da norma constitucional.

Temos, então, muitas vezes, mutações, ou melhor, modificações não formais das constituições, que não são de forma alguma inconstitucionais. Mas há mutações ou modificações não formais que são 
claramente inconstitucionais. Refirome, por exemplo, no nosso caso, às medidas provisórias, caso exemplar.

A posssibilidade de edição de atos normativos primários por parte do Poder Executivo tornou-se uma exigência do Estado contemporâneo, intervencionista em diversos planos, para fazer face a situações conjunturais, sobretudo econômicas. Esta nova realidade fez com que se superasse o modelo clássico segundo o qual cabia ao Poder Executivo tão somente elaborar normas estritamente subordinadas à lei, os denominados regulamentos de execução. Passou-se, assim, a admitir, desde o início do século passado e nos mais diversos sistemas constitucionais, a competência de o Poder Executivo editar normas com força de lei, atos normativos primários, chamemse elas lei delegadas, dependentes de autorização prévia do Poder Legislativo, ou decretos leis e medidas provisórias, geralmente sujeitos a apreciação posterior do Poder Legislativo.

Nosso anterior ordenamento constitucional previa tanto as leis delegadas como os decretos leis, estes últimos substituídos, com a promulgação da Constituição de 1988, pelas medidas provisórias, inspiradas na experiência italiana.

O problema diz respeito não propriamente à existência das medidas provisórias, mas ao largo abuso em sua utilização, atestado, por exemplo, antes da promulgação da Emenda
Constitucional n ${ }^{\circ} 32$ de 2001, alterando o Artigo 62 da Constituição, por suas contínuas reedições, tornando-as praticamente "permanentes".

Trata-se de medidas legislativas de urgência,indispensáveis nocontextoda sociedade contemporânea; constituem instrumento ágil de intervenção legislativa do Poder Executivo para situações emergenciais, mas foram abastardadas pela prática institucional. Desde já há muito, governa-se através de medidas provisórias. A Emenda Constitucional $n^{\circ} 32$ de 2001 tentou aperfeiçoar o status constitucional das medidas provisórias, mas ficou aquém do desejável. Assim, continuamos em grande parte ainda a ser governados através de medidas provisórias. Dessa forma, rompemos com a intenção constitucional. Tratase de uma modificação não formal da Constituição, contrariando a sua inspiração e os seus objetivos.

Então, por mais que façamos, sendo importantes, sem dúvida, mudanças constitucionais ou mudanças infraconstitucinais, enfrentamos sempre alguns pontos de estrangulamento, que dizem respeito sobretudo às práticas inconstitucionais dos poderes, em especial do Executivo.

Gostaria de finalizar, acentuando a importância de resgatarmos, sim, uma cultura republicana, uma cultura política republicana, que não diz respeito propriamente e nem deve dizer respeito simplesmente a um 
conhecimento preciso, sistemático nistrativas, superando o tratamento da e metodológico do que sejam os coisa pública como coisa privada, a princípios republicanos. Refiro- indistinção entre a dimensão pública me ao que os cientistas políticos e a dimensão privada, que permeiam e sociólogos caracterizam como as três esferas do Estado Federal de cultura política, envolvendo afeições, maneira geral, ressalvada as justas comportamentos, postura, ética, para, exceções, não conseguiremos transenfim, construirmos, uma efetiva formar a Constituição em algo querirepública no Brasil, que é um objetivo do pela sociedade. Para construirmos a ser almejado pela sociedade. sentimento constitucional (Karl Lo-

Seguramente, são importantes reformas constitucionais e legislativas para sinalizarem caminhos e marcarem fronteiras. Mas se nós não tiver- republicanas. Essa a mensagem que mos um processo de refundação das gostaria de deixar ao final de minha práticas políticas, das práticas admi- intervenção. 